\begin{tabular}{|c|c|}
\hline & Volume \& Issues Obtainable at The Women University Multan \\
& Annals of Social Sciences and Perspective \\
& ISSN: 2707-7063, Volume 1, No.2 December 2020 \\
\hline
\end{tabular}

\title{
Relationship between Self-Esteem, Jealousy and Anger in Emerging Adults
}

\author{
Ayesha Farooq ${ }^{1}$, Shazia $\operatorname{Irfan}^{2}$, Sehrish Farooq $^{3}$
}

\begin{abstract}
The present cross-sectional study explored the relationship between self-esteem, jealousy and anger in young adults. Researchers hypothesized that self-esteem would be negatively correlated with jealousy and anger; jealousy and anger will be positively related to each other. Low self- esteem was proposed as a predictor of jealousy and anger. A convenient sampling technique was used to draw a sample of 200 young adults $(M=100, W=100)$. Correlation analysis, simple linear regression and t-test were used. As per results, self-esteem was negatively related to jealousy and anger. Jealousy was positively related to anger. Low Selfesteem significantly predicted jealousy and anger. Furthermore, significant differences in selfesteem were observed for both genders as women scored higher for self-esteem but no significant differences were found on jealousy and anger. Also, significant differences in the family system for self-esteem and jealousy were found. Participants who belonged to the joint family system scored high on jealousy, whereas those from the nuclear family were high on self-esteem. Study implications are discussed with its application in clinical, counselling, educational and domestic settings.
\end{abstract}

Keywords: Self-esteem, Jealousy, Anger, Emerging Adults

\section{Introduction}

Young adulthood is a stage of transition and adjustment to new changes in life. In this stage, they are assigned and expected to play different roles such as a spouse, parent and decision maker with mature behavior. These expectations and assignments of new roles can cause adjustment problems in adulthood. A continuous struggle to behave like mature adults refrains them to seek guidance from others and causes difficulty in coping with adjustment issues alone which ultimately leads to certain emotional disturbance. Adults often experience low selfesteem when they couldn't meet the set criteria for them or fail to perform expected roles well. This threat to self-esteem can lead to emotional disturbance and they often experience blended emotions involving embarrassment or jealousy when they see others performing better than them. Stieger, Preyss and Voracek (2012) explained that the emotion of jealousy is often associated with low or damaged self-esteem.

\footnotetext{
${ }^{1}$ PhD Scholar, Institute of Applied Psychology University of Punjab, Lahore; ayeshafarooq1011@gmail.com

${ }^{2}$ Associate Professor, Govt. Post Graduate College for Women Samanabad, Lahore; shaziairfan2033@gmail.com

${ }^{3}$ PhD Scholar, Institute of Applied Psychology University of Punjab, Lahore; sehrishfarooq.pu@ gmail.com
} 
Self-esteem refers to the degree to which a person appreciates and values himself or herself. Self- worth and self-esteem develop when people interact with others and compare their ideas, skills and performance with others. This interaction with society can affect their self-esteem in positive or negative manners. Others possession can threaten their self-esteem and some kind of social comparison may cause jealousy or envy in them. Those with a high level of selfesteem have been found extreme confident about their abilities while low self-esteem leads them to numerous psychological and social issues (Srivastava \& Agarwal, 2013). Hopelessness and lack of confidence in one's abilities develop a sense of competition in them. A certain level of competition can be healthy and motivating for them but a continuous feeling of incapable and unworthy can leads to unhealthy competition. Social comparison directed them to display envy and anger to maintain their social status and position. Perception of inadequacy and cognitive dissonance or discrepancy between real and ideal self also affect self-esteem and provokes jealousy. Parker et al, (2005) linked self-esteem with an individual's vulnerability to jealousy. The young adolescents were surveyed about their jealousy as well as their perceived jealousy of their peers. Analysis of the data revealed that jealousy was linked with feelings of self-worth, loneliness and dissatisfaction with peers and friends.

Jealousy is the most common emotional response observed in humans as a threat to self-esteem, competition and rejection. It is an emotional reaction to risking self-esteem and rejection. Adults, who experience jealousy, incline to have low self-esteem and reported experience blended emotions of depression, unhappiness, sadness, embarrassment and anxiety (Parker, Low, Walker, \& Gamm, 2005) and contribute to dissatisfaction. Expression of jealousy may vary from person to person however anger becomes the common outburst of the creepy feeling of jealousy. Unhealthy expression of jealousy and anger not only disturbs their mental health but their present or future relationships. Jang, et.al (2014) highlighted the negative effects of anger indicating its role in suicidal thoughts and ideation. Adams (2012) also confirmed the connection between self-esteem and jealousy. Jealousy and anger can cause a person to lose control of what he/she says, does and thinks during heated moments, and the consequences can be devastating. Anger is said to have a more strong connection with jealousy than other basic sentiments (Shaver, Schwartz, Kirson \& O'Connor, 1987). Hence the goal of this study was to highlight the association between self- esteem, jealousy and anger in emerging adults and to explore gender differences between study variables.

\section{Hypotheses}

H1: Self-esteem would be negatively associated with jealousy and anger in emerging adults.

H2: Jealousy and anger would likely be positively associated with each other.

H4: Low self-esteem would likely predict jealousy and anger.

H5: There would be gender and family system differences in self-esteem, jealousy and anger in emerging adults. 


\section{Method Research Design}

The research was cross-sectional based on a correlational design.

\section{Sample}

Following a convenient sample, a non-probability technique, the sample was drawn comprising of 200 adults $(\mathrm{M}=100, \mathrm{~W}=100)$ between 18-23 years old (Mean=21.17, SD=1.19). Among them, $137(68.5 \%)$ belong to the joint while $63(31.5 \%)$ belong to the nuclear family system. Qualification of 105 adults (52.5\%) was graduation while 95 (47.5\%) were from masters.

\section{Assessment Measures}

Demographic Sheet. It involved information about the age, gender, qualification and family system of the participants.

The Rosenberg self-esteem scale (Rosenberg, 1965). To assess self-esteem, participants filled a 10-items scale based on a 4-point Likert scale ranging from strongly agree $=1$ to strongly disagree $=4$. The reliability of RSES ranges from 0.77 to 0.88 (Rosenberg, 1965).

Interpersonal jealousy scale (Farooq \& Amjad, 2012). To measure jealousy, the indigenous scale of interpersonal jealousy (Farooq \& Amjad, 2012) was considered. The scale consisted of 25 items (when someone is wealthier than me, I think of snatching all things away from $\mathrm{him} / \mathrm{her}$ ). All items were rated on a 5 point Likert scale (1=strongly disagree to $5=$ strongly agree). The reliability of the scale is 80 (Farooq \& Amjad, 2012).

Clinical anger scale (Snell, et al. 1995). A 21-items scale of anger having four levels was used to assess anger. All items were rated on a four point Likert scale $(0=\mathrm{A}, 1=\mathrm{B}, 2=\mathrm{C} \& 3=\mathrm{D})$ ranges from minimal anger to severe anger.

\section{Procedure}

Respondents were briefed about the study and formal consent was taken from them to participate. They were provided the right to leave the study anytime they wish to. Their volunteer participation was insured. They were briefed about the questionnaires and any ambiguity was clarified. Participants took 15-20 minutes to fill the questionnaires. Gratitude was shown to them for their time and participation.

\section{Results}

Pearson product moment correlation was run to highlight the relationship between self-esteem, jealousy and anger and demographic variables including gender and family system. The result indicated a negative relationship between self-esteem, jealousy and anger. Jealousy was positively related to anger. Among demographic variables family system showed negative relation with self- esteem and positive relation with jealousy whereas no relation was found with anger (See table 1). 
Table 1: Bivariate Correlation between Self-Esteem, Jealousy and Anger $(\mathbf{n}=200)$

\begin{tabular}{lllllll}
\hline & Variables & 1 & 2 & 3 & 4 & 5 \\
\hline 1 & Gender & - & $.18^{* *}$ & .13 & -.00 & -.04 \\
2 & Family system & & - & $-.13^{*}$ & $.19^{* *}$ & .05 \\
3 & Self-esteem & & - & $-.15^{*}$ & $-.14^{*}$ \\
4 & Jealousy & & & - & $.17^{*}$ \\
5 & Anger & & & & - \\
\hline
\end{tabular}

Note: $* p<.05, * * p<.01, * * * p<.001$, for gender men $=0$, women $=1$, for family system $0=$ nuclear, $1=$ joint

Further, linear regression was run to evaluate self-esteem as a predictor of jealousy and anger (see Table 2). Before the main analysis, relevant assumptions were checked. Collinearity statistics i.e. VIF and Tolerance were within acceptable limits. The data met the assumption of independent errors (Durbin-Watson value $=1.20,1.91$ ).

Table 2: Linear Regression Analysis for Self-Esteem as a predictor of Jealousy and Anger $(\mathbf{n}=\mathbf{2 0 0})$

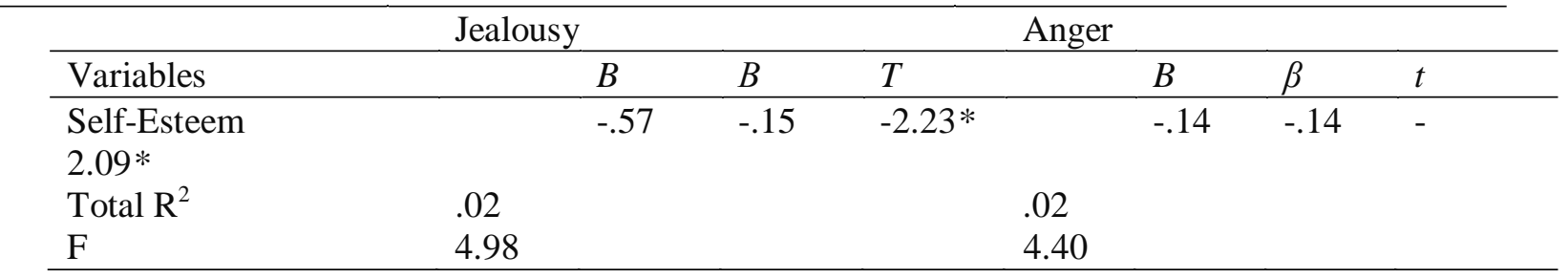

Note: ${ }^{*} p<.05, * * p<.01, \beta=$ standardized beta,

The result of linear regression revealed low self-esteem a significant and important predictor of jealousy $F(1,198)=4.98, p<.05$ and anger $F(1,198)=4.40, p<.05$.

An independent sample t-test was run to assess the differences among genders in self-esteem, jealousy and anger. Results exhibited significant differences in self-esteem as women were high on their level of self-esteem whereas no significant gender difference was found on jealousy and anger (See table 3)

Table 3: Independent Sample t-test to Compare Men and Women $(\mathbf{n = 2 0 0})$

\begin{tabular}{llllllll}
\hline \multirow{2}{*}{ Variables } & $\begin{array}{l}\text { Men } \\
(\mathrm{n}=100)\end{array}$ & $\begin{array}{l}\text { Women } \\
(\mathrm{n}=100)\end{array}$ & & & $95 \% \mathrm{CI}$ & \\
\cline { 2 - 8 } & $M(S D)$ & $M(S D)$ & $T$ & $p$ & $L L$ & UL & Cohen's d \\
\hline Self-esteem & $14.94(3.02)$ & $15.74(2.91)$ & -1.90 & $.05^{*}$ & -1.62 & .028 & .26 \\
Jealousy & $74.18(11.20)$ & $74.04(10.82)$ & .09 & .92 & -2.93 & 3.21 & .01 \\
Anger & $23.97(2.67)$ & $23.69(3.07)$ & .68 & .49 & -.52 & 1.08 & .09 \\
\hline
\end{tabular}


Note $* p<.05, M=$ mean, $S D=$ Standard deviation, $p=$ significance level, $U L=$ upper limit, $L L=$ lower limit, $C I=$ confidence interval

Further, t-test was run to find the difference in the family system on jealousy and anger and self- esteem. (See table 4)

Table 4: Independent Sample t-test to Compare Joint and Family System $(n=200)$

\begin{tabular}{llllllll}
\hline \multirow{2}{*}{ Variables } & $\begin{array}{l}\text { Nuclear } \\
(\mathrm{n}=100)\end{array}$ & $\begin{array}{l}\text { Joint } \\
(\mathrm{n}=100)\end{array}$ & & & $95 \% \mathrm{CI}$ & \\
\cline { 2 - 8 } & $M(S D)$ & $M(S D)$ & $T$ & $P$ & $L L$ & $U L$ & Cohen's $d$ \\
\hline Self-esteem & $15.95(2.60)$ & $15.05(2.91)$ & 2.11 & $.03^{*}$ & .058 & 1.72 & 0.32 \\
Jealousy & $71.03(13.17)$ & $75.52(9.54)$ & -2.43 & $.01^{* *}$ & -8.16 & -.82 & 0.39 \\
Anger & $23.58(2.80)$ & $23.94(9.85)$ & -.80 & .41 & -1.21 & .50 & -0.04 \\
\hline
\end{tabular}

Note $* p<.05, * * p<.01, S D=$ Standard deviation, $M=$ mean, $p=$ significance level, $C I=$ confidence interval, $U L=$ upper limit, $L L=$ lower limit

Results revealed significant differences in the family system on self-esteem and jealousy. Sample from joint family scored more on jealousy, whereas participants from nuclear systems scored more on self-esteem. No significant differences were found in anger.

\section{Discussion}

The study planned to highlight the relationship between self-esteem, jealousy and anger in emerging adults. It was hypothesized that self-esteem is negatively related to jealousy and anger. It was further hypothesized that Jealousy and anger will be positively related. The findings of the study confirmed the hypotheses. The study also found self-esteem as a predictor of jealousy and anger. In line with existing researches, findings supported the hypotheses. Lazarus (1994) maintained low self-esteem as a strong base for jealousy.

DeSteno, Valdesolo and Bartlett (2006), in an experimental study, confirmed threatened selfesteem as a primary mediator of jealousy. A person with low self-esteem is most inclined toward the experiences of jealousy and demonstrate characteristics of being insecure and dependent (Meaney, Stewart \& Beatty, 1985). Adams (2012) also supported the negative association between jealousy and self-esteem. Hamid (2013) determined the negative association between jealousy components and self-esteem. Cooley (2006) also investigated the significant relationship between jealousy, locus of control and self-esteem. Parker et al, (2005) linked self-esteem with children's and adolescents' vulnerability to jealousy especially when surrounding friends. Most of the causes of jealousy can be attributed to low self-esteem.

Self-esteem also has a relationship with anger when people lack self-esteem; they blame others to overcome their dissatisfaction. Anger is the common outburst of the feeling of inadequacy. Brooks-Gunn (1984) supported more anger expression among low self-esteem individuals. The female expression is usually internal while the male show direct and outer hostility. Cha and Sok (2014) explored significant results for anger expression, depression and self-esteem in nurses. Arslan (2009) found perceived social support, self-esteem and anger to be negatively associated with each other. 
Jealousy also leads to different blended emotions of insecurity, anger, fear and sadness. People usually use any form of anger to express they suppress emotions when they find no or little control over the circumstances. The intention of dominating others leads them to overt anger and physical or verbal 1 aggression (Archer \& Webb, 2006). Bryson (1976) also confirmed a desire for revenge in envious individuals.

As Western culture has expressed, jealousy is the green-eyed monster, then anger is responsible for readying the monster and jealousy provides the eye to detect the threat. Jealousy is an outgrowth of anger. Anger is the precursor of jealousy and every expression of jealousy includes some amount of anger (Hart, 2010). Anger and jealousy can cause a person to lose control of what he/she says, does and thinks during a heated moment and the consequences can be devastating. Anger moves the individual towards and against the source of jealous feelings. Guerrero (1998) and sharpen steel (1991) explored the attachment related factors and found that anxiously attached people experience jealousy in more intense ways than others. These individuals experienced embarrassment, fear, sadness and anger during jealousy eliciting events. Anger can be expressed from simple to full blown out of control rage.

Besides other factors, family setup and environment can also develop and modify an individual's emotional expression to a certain situation. Individuals interact with their family more than other people on a routine basis, therefore, the setup of the family may also affect their self-esteem in healthy or unhealthy ways. Competition, criticism and negativity within the family lead to intense feelings of jealousy. So the study also attempted to search the differences in the family system in self-esteem, jealousy and anger. Significant but slight differences were observed in self-esteem and jealousy. Participants who belonged to the nuclear family system scored slightly above on self-esteem. Findings of Shi, et.al (2017) study supported that individuals from child families or brought up by parents without grandparents showed high self-esteem than others. As people living in nuclear families are independent in their decisions, they have a greater worth of their self and self-dependency. Participants from the joint family system score more on jealousy. People living in the joint family system have more people around them to compete with, as result, they develop feelings of jealousy and other negative emotions when not meeting with challenges or not getting the same things that others have.

Furthermore, gender differences were also explored. Small but significant results were found for self-esteem as women scored more on self-esteem than men. These results for gender differences were contrary to previous research which founded men higher on self-esteem as compared to women (Quatman \& Watson, 2001; Marcotte, Fortin, Potvin, \& Papillion, 2002; Moksnes \& Espnes, 2013). However, Watkins, Dong and Xia (1997) showed an indication of gender differences as girls higher on self-esteem than boys.

\section{Conclusion}

This study has contributed to existing literature leading to several future types of research on the impact of self-esteem on jealousy and anger. Additionally, it can help clinicians to develop better strategies and therapeutic interventions to overcome undesirable emotions such as jealousy, managing anger and enhance self-esteem. Emerging adults can be counsel to deal with changes in their life in a better way and to participate in healthy activities to attain a high level of self-esteem and avoiding harm to themselves and others.

Like other studies, this study also faced some limitations. It was quantitative and thus limiting 
the in-depth exploration of study variables. Future researches can further explore the role of social competition in lowering self-esteem. Family related factors can also be explored in detail.

\section{References}

Adams, S. (2012). Jealousy in romantic relationships, self-esteem and ego defenses (Doctoral dissertation, Victoria University).

Archer, J., \& Webb, I. A. (2006).The relation between scores on the Buss-Perry Aggression Questionnaire and aggressive acts, impulsiveness, competitiveness, dominance, and sexual jealousy. Aggressive Behavior, 32(5), 464-473. https://doi.org/10.1002/ab.20146

Arslan, C. (2009). Anger, self-esteem, and perceived social support in adolescence. Social Behavior and Personality: an international journal, 37(4), 555-564. https://doi.org/10.2224/sbp.2009.37.4.555

Brooks-Gunn, J. (1984). The psychological significance of different pubertal events to young girls. The Journal of Early Adolescence, 4(4), 315-327. https://doi.org/10.1177/0272431684044003

Bryson, J. B. (1991). Modes of Response to Jealousy-Evoking. The psychology of jealousy and envy, 178.

Cha, N. H., \& Sok, S. R. (2014).Depression, self-esteem and anger expression patterns of Korean nursing students. Internationalnursing review, 61(1), 109-115. https://doi.org/10.1111/inr.12076

Cooley, R. C. (2006). Correlational Relationship between Jealousy, Self-Esteem, and Locus of Control in an Undergraduate Population. Senior Honors Theses 18.

DeSteno, D., Valdesolo, P., \& Bartlett, M. Y. (2006). Jealousy and the threatened self: Getting to the heart of the green-eyed monster. Journal of personality and social psychology, 91(4), 626.https://doi.org/10.1037/0022-3514.91.4.626

DeSteno, D., Valdesolo, P., \& Bartlett, M. Y. (2006). Jealousy and the threatened self: Getting to the heart of the green-eyed monster. Journal of personality and social psychology, 91(4), 626.https://doi.org/10.1037/0022-3514.91.4.626

Farooq, S., \& Amjad, N. (2012). Construction and validation of the Jealousy scale. (Unpublished research). Institute of Applied Psychology, University of the Punjab, Lahore.

Guerrero, L. K. (1998). Attachment-style differences in the experience and expression of romantic jealousy. Personal Relationships, 5(3), 273-291. https://doi.org/10.1111/j.1475- 6811.1998.tb00172.x

Hamid, M. (2013).The relationship of self-esteem with jealousy in athletes and neurotic patients of Behbahan Province. Annals of Biological Research, 4(8), 191-195.

Hart, S. L. (2010). The ontogenesis of jealousy in the first year of life: A theory of jealousy as a biologically-based dimension of temperament. In S. L. Hart \& M. Legerstee (Eds.), Handbook of jealousy: Theory, research, and multidisciplinary approaches (p. 57-82). Wiley Blackwell. https://doi.org/10.1002/9781444323542.ch4

Jang, J. M., Park, J. I., Oh, K. Y., Lee, K. H., Kim, M. S., Yoon, M. S., \& Chung, Y. C. (2014).

Predictors of suicidal ideation in a community sample: roles of anger, self-esteem, and depression. Psychiatry Research, 216(1), 74-81. https://doi.org/10.1016/j.psychres.2013.12.054.

Lazarus, R. S. (1991). Progress on a cognitive-motivational-relational theory of emotion. American psychologist, 46(8), 819. 
Marcotte, D., Fortin, L., Potvin, P., \&Papillon, M. (2002). Gender differences in depressive symptoms during adolescence: Role of gender-typed characteristics, self-esteem, body image, stressful life events, and pubertal status. Journal of Emotional and Behavioral Disorders, 10(1), 29-42. https://doi.org/10.1177/106342660201000104.

Meaney, M. J., Stewart, J., \& Beatty, W. W. (1985). Sex differences in social play: The socialization of sex roles. In Advances in the Study of Behavior (Vol. 15, pp. 158).Academic Press.https://doi.org/10.1016/S0065-3454(08)60486-6.

Moksnes, U. K., \& Espnes, G. A. (2013).Self-esteem and life satisfaction in adolescentsgender and age as potential moderators. Quality of Life Research, 22(10), 2921-2928.

Parker, J. G., Low, C. M., Walker, A. R., \& Gamm, B. K. (2005). Friendship jealousy in young adolescents: individual differences and links to sex, self-esteem, aggression, and social adjustment. Developmental psychology, 41(1), 235. https://doi.org/10.1037/00121649.41.1.235.

Quatman, T., \& Watson, C. M. (2001). Gender differences in adolescent self-esteem: An exploration of domains. The Journal of genetic psychology, 162(1), 93-117. https://doi.org/10.1080/00221320109597883

Rosenberg, M. (1965). Rosenberg self-esteem scale (RSE). Acceptance and commitment therapy. Measures package, 61, 52 .

Sharpsteen, D. J. (1991). The organization of jealousy knowledge: Romantic jealousy as a blended emotion.

Shaver, P., Schwartz, J., Kirson, D., \& O'connor, C. (1987). Emotion knowledge: Further exploration of a prototype approach. Journal of personality and social psychology, 52(6), 1061.

Shi, J., Wang, L., Yao, Y., Su, N., Zhao, X., \& Chen, F. (2017). Family impacts on self-esteem in Chinese college freshmen. Frontiers in psychiatry, 8, 279. https://doi.org/10.3389/fpsyt.2017.00279

Snell Jr, W. E., Gum, S., Shuck, R. L., Mosley, J. A., \& Kite, T. L. (1995). The clinical anger scale: preliminary reliability and validity. Journal of Clinical Psychology, 51(2), 215226.https://doi.org/10.3389/fpsyt.2017.00279

Srivastava, N., \& Agarwal, S. (2013). Self-esteem among young adults: A comparative study. International Journal of Humanities and Social Science Invention, 2(3), 59-61.

Stewart, R. A., \& Beatty, M. J. (1985). Jealousy and self-esteem. Perceptual and motor skills, 60(1), 153-154.https://doi.org/10.2466/pms.1985.60.1.153

Stieger, S., Preyss, A. V., \& Voracek, M. (2012). Romantic jealousy and implicit and explicit self- esteem. Personality and Individual Differences, 52(1), 51-55. https://doi.org/10.1016/j.paid.2011.08.028

Watkins, D., Dong, Q., \& Xia, Y. (1997).Age and gender differences in the self-esteem of Chinese children. The Journal of social psychology, 137(3), 374-379. https://doi.org/10.1080/00224549709595448. 